América sin Nombre, n. ${ }^{\circ} 25$ (2021): 65-74

ISSN: 1989-9831

DOI 10.14198/AMESN.2021.25.05

Fecha de recepción: 24/04/2020

Fecha de aceptación: 20/05/2020
Modo de citación de este artículo:

Girona, Nuria. "Voz y cuerpo autoriales en Juana Manso». Imaginarios, naciones y escritura de mujeres del siglo XIX en América Latina. Remedios Mataix y Brigitte Natanson (coordinadoras). América sin Nombre, 25 (2021): 65-74, DOI: 10.14198/AMESN.2021.25.05

Link para este artículo: https://doi.org/10.14198/AMESN.2021.25.05

\title{
Voz y cuerpo autoriales en Juana Manso
}

\author{
Voice and authorial body in Juana Manso
}

\author{
Nuria Girona* \\ Universidad de Valencia \\ nuria.girona@uv.es \\ https://orcid.org/0000-0002-0023-6406
}

\section{Resumen}

El estilo de Juana Manso fue calificado por Sarmiento como «escandaloso». Esa manera inequívoca de presentarse públicamente delimitó desde entonces un modo de existencia, de circulación y de funcionamiento de su figura autorial en el campo cultural argentino de mediados de siglo xix. Este artículo se propone rastrear esta singular "puesta en escena» de la escritora como un dispositivo de enunciación que no se limita a sus textos, en la doble dimensión que ocupa, como autora y como actora de ese campo. ¿Cómo se construye, en esta puesta escena, su voz y su imagen?, ¿Cómo se difunde ese cuerpo de autora? En la conjunción de género y profesión, la función-Manso se concreta en un tono de escritura y un modo de actuar como escritora, es decir, en un estilo de feminidad. En sus autorrepesentaciones se detecta un desajuste entre los ideales de género de la época y la manera de enfrentarlos. La monstruosidad se cuela en estas referencias: el cuerpo retorna inquietante en las figuras que la subjetividad impone al discurso.

Palabras clave: Juana Manso; autoría; puesta en escena; cuerpo; feminidad.

\begin{abstract}
Juana Manso's style was described by Sarmiento as «scandalous». This unequivocal way of presenting itself publicly has since defined manner of existence, circulation and operation of hers authorial figure in the Argentine cultural field of the mid-nineteenth century. This article proposes to trace this singular «staging» of the writer as a device of enunciation that is not limited to her texts, in the double dimension that she occupies, as an author and as an actor in that field. How is her voice and image constructed in this staging? How is that author's body transmitted? In the conjunction of gender and profession, the Manso function takes the form of a tone of writing and a way of acting as a writer, that is to say, a style of femininity. In her self-representations there is a mismatch between the gender ideals of the time and the way of dealing with them. The monstrosity sneaks into these references: the body returns unsettling in the figures that subjectivity imposes on the discourse.
\end{abstract}

Keywords: Juana Manso; authorship; staging; body; femininity.

\footnotetext{
* Profesora titular del Departamento de Filología Espańola de la Universitat de València. Sus investigaciones se centran en el ámbito de la literatura latinoamericana, los Estudios Culturales y los Estudios de Género, con particular interés en los géneros limítrofes como la novela histórica, el testimonio o la autobiografía. Entre sus publicaciones destacan: Escrituras de la historia. La novela argentina de la dictadura militar (1995), Rituales de la verdad. Mujeres y discursos en América Latina (2008), la edición crítica de Tala y Lagar de Gabriela Mistral (2001) y Vida de Sor Francisca Josefa del Castillo (con B. Ferrús, 2009) y la compilación La cultura en tiempos de desarrollo: violencias, contradicciones y alternativas (2012).
}

\section{(C) 2021 Nuria Girona}


«Ora, pois, uma senhora à testa da redação de um jornal! Que bicho de sete cabeças será?» escribe Juana Manso cuando presenta el primer número de O Jornal das Senhoras. Modas, litteratura, bellas artes, theatros e critica ${ }^{1}$, el periódico que funda en Brasil en 1852. La presuposición del monstruo de siete cabezas anticipa la reacción del público ante su aspiración de dirigir un semanario. Sin duda es un atrevimiento, pero como indica, los ejemplos de publicistas abundan en Francia, Inglaterra, Italia, Estados Unidos y Portugal. América no puede quedarse al margen del progreso. Llega entonces a Río de Janeiro este periódico «redigido por uma Senhora mesma: por uma americana que, senáo possue talentos, pelo o menos tem a vontade e o desejo de propagar a ilustração, e cooperar com todas as suas forças para o melhoramento social e para a emancipação moral da mulher» $(O J S, \mathrm{I}, 1,1852)$.

Es solo el comienzo de una práctica periodística en donde muestra tanto la conciencia de su actividad profesional como lo insólito e inadecuado que resulta. Ya nunca abandonará este medio que facilita la difusión urgente de su ideario pedagógico y gana terreno a otros géneros. Aunque los distintos semanarios que fundó o en los que participó le sirven para presentar por entregas dos novelas, dar a conocer ciertos apuntes autobiográficos o partes de un diario de viajes, estos géneros no dejan de supeditarse a la prensa, si tenemos en cuenta que solo publica como libro La familia del Comendador (1854). Es a través de estas colaboraciones que Manso aspira no solo a un espacio de reconocimiento en el campo letrado sino a un lugar de intervención en el proyecto nacional argentino de mediados del siglo XIX.

En O Jornal das Senhoras se gestan también las reivindicaciones alrededor de la educación femenina y lo que considera «emancipación moral de la mujer», reelaboradas posteriormente en periódicos argentinos como Álbum de Señoritas, La Ilustración Argentina o La Flor del Aire. A la conciencia de su actividad profesional le acompańa la necesidad, no solo de educar a las mujeres, sino de formar en ellas una conciencia como tales. Si los rígidos códigos de género de la época no le permitieron llegar más allá

1. El semanario circuló entre 1852 y 1855 , aunque Manso apenas lo dirigió el primer año. La cita corresponde al tomo 1 , página 1 , de 1852 , siguiendo la numeración que presentan los archivos de la Hemeroteca Digital da Biblioteca Nacional de Brasil (http://bndigital.bn.gov.br/hemeroteca-digital), citado a partir de ahora de forma abreviada $(O J S)$, por ese orden y respetando la lengua y gramática del original. de la defensa del matrimonio igualitario o la maternidad republicana, lo que resulta de avanzada es la llamada a una identidad colectiva entre las mujeres y el impulso por afirmar su subjetividad, hasta entonces anulada. "O que vem a ser a mulher?» se pregunta en el número inaugural del semanario brasileño, como veremos más adelante. De su naturaleza depende también la legitimidad del ejercicio del periodismo y el oficio de la literatura.

En el reconocimiento de la autoría femenina de ese momento se juegan ambas cuestiones: ser mujer y ser escritora. En ese sentido, Graciela Batticuore ha señalado que uno de los gestos más desafiantes de Manso fue el de exhibir su nombre al completo al frente de Álbum de Señoritas y proclamar así la propiedad de sus textos (129 y ss.) $)^{2}$. El gesto inaugura justamente, según Batticuore, a través de la prensa femenina de mitad de siglo, el modelo de la «autoría apropiada y exhibida» y evidencia, pese a las reticencias de los letrados varones, la emergencia de la escritora pública. En el momento en que debuta como periodista "parece consciente de las dificultades que plantea la autoría a las mujeres. Y tienta algunas formas de afrontarla» (132).

Una manera de afrontarla fue mostrar la continuidad entre las tareas de la escritora y las que se atribuían a su sexo ${ }^{3}$. Las alusiones al oficio en Manso se presentan entrelazadas con sus autorreferencias como madre o como maestra. No se trata solo de mostrar que era posible simultanear tareas intelectuales y domésticas; tampoco consiste solo en instruir a madres competentes para incidir en el ámbito familiar y así en la construcción de la nación argentina. Si el género asigna tanto papeles como espacios a los dos sexos, Album postuló la creación de un espacio nuevo, intermedio, entre la esfera pública masculina

2. Álbum de Señoritas. Periódico de Literatura, Modas, Bellas Artes y Teatros fue fundado a su vuelta a Argentina, en 1854. Tan solo se publicaron ocho números dada la falta de suscripciones y el rechazo que provocó. Todas las referencias a este periódico están tomadas de la reproducción que se encuentra en el portal dedicado a Juana Manso: http://www. juanamanso.org/, citadas abreviadamente (ÁS) a partir de ahora y con la numeración que presenta el documento que se descarga. Se ha respetado la gramática del original.

3. Como referencia, tan solo citaré al respecto el precedente de 1830, de La Aljaba. La publicación, «dedicada al bello sexo", cuya redactora se mantiene en el anonimato, que resume, en su Prospecto, los lugares por excelencia reservados a la mujer: «hijas obedientes, madres respetables y dignas esposas» (ctd. en Auza 31). 
y la esfera privada femenina. Esta "zona alternativa» (Meyer 123) era el lugar desde el cual la mujer podría participar activamente en los debates sobre temas de actualidad sin abandonar sus obligaciones caseras.

No es casual que, como apunta Francine Masiello, la escritora exponga la necesidad de dinero para mantener a su hijo cuando apela al apoyo financiero del Álbum: «La revista, en efecto, era un hijo más; y para criar al ciudadano nuevo (en este caso, formado por la república de las letras), había que sostenerlo por medio de las suscripciones. De esta manera, Juana Manso llegaba a la esfera pública, siempre a condición de que entrara en su papel de madre» (40). Producción textual y reproducción biológica se entrecruzan en esta apelación en donde el ejercicio de la escritura permite sostener la crianza del hijo.

Los deberes del género se funden así con los profesionales y los personales. El «ser femenino» se construye a golpe de mandatos culturales y exigencias individuales. Manso alude a «su destino de madre» como una obligación, a la par de las que conlleva el magisterio que ejercerá en su vida y en la prensa, y de las que involucra su "carrera literaria» (así la denomina). Las necesidades se confunden con las pretensiones y los requerimientos se disfrazan de elecciones. Lo público conforma lo privado y a la inversa. En este sentido, afirma Lelia Area:

Lo insoportable en ella será, entonces, el hecho de que intente ocupar ambos espacios sin tener ninguno de los respaldos tradicionales a sus espaldas: dinero, familia, nombre o marido. Era insoportable tanto para los hombres como para las mujeres del Buenos Aires posrosista porque sus pretensiones la mostraban carente y solvente, a la vez. Carente, solvente e insolente dado que no tenía reparos en exponer tanto sus créditos como sus réditos sin maquillaje alguno (48).

«Lo insoportable» de Manso no proviene entonces solo de sus ideas sobre la emancipación femenina o la educación laica, no viene solo de la exhibición de la autoría. También las maneras y recursos que encuentra para insertarse en la escena cultural son los que

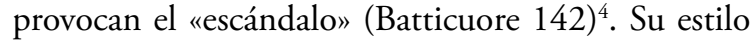

4. Batticuore recuerda la carta de Sarmiento, de 1867, que advierte a Manso sobre esta acusación: «Sabe usted de otra argentina que ahora o antes haya escrito, hablado o publicado, trabajado por una idea útil, compuesto versos, redactado un diario? Una mujer pensadora es un escándalo» (150). irrita, resulta intolerable y la diferencia de las demás escritoras y de las demás mujeres.

Ese estilo, esa manera inequívoca de escribir y presentarse me servirán, en las páginas sucesivas, para indagar cómo, más allá de la firma y la instancia creadora, el nombre de Juana Manso «funciona para caracterizar un determinado modo del ser del discurso" (Foucault 338) ${ }^{5}$, es decir, delimita un modo de existencia, de circulación y de funcionamiento de la incipiente autoría. Rastrearé, por tanto, en esta singular manera de ocupar una posición en el campo literario, un dispositivo de enunciación que no se limita a sus textos, en la doble dimensión que ocupa, como autora y como actora de este campo. Me interesa fundamentalmente delimitar la puesta en voz propia y ajena de ese cuerpo autorial. En la conjunción de género y profesión que he expuesto, la función-Manso se concreta en un estilo de escritura y de escritora, es decir, en un estilo de feminidad. El «bicho de siete cabezas» no solo alude al atrevimiento de dirigir un periódico sino a una manera de vivir esa feminidad, en cierta manera monstruosa, como veremos. Porque esa imagen espantosa se repite en sus escritos: el cuerpo retorna inquietante en las figuras que la subjetividad impone al discurso.

En esas imágenes se detecta un desajuste entre los ideales de género en la época y la manera de enfrentarlos por parte de Manso. Con este propósito retomaré la descripción de esos rasgos de estilo que planteaba para analizar después algunas de sus autorrepresentaciones y figuraciones como escritora, y terminar con sus reflexiones sobre la feminidad.

\section{Las puestas en escena de Manso}

Un estilo de escritura y de actuación particulariza a Manso, como explicaba anteriormente, un ethos discursivo (Mainguenau 2010) en correlación con sus

5. Acompaño la ya clásica pregunta de Foucault de la variable de género: "Un nombre de autor no es simplemente un elemento en un discurso [...]; ejerce un determinado papel con relación al discurso: garantiza una función clasificatoria; un nombre semejante permite reagrupar un determinado número de textos, delimitarlos, excluir algunos, oponerlos a otros... el nombre de autor funciona para caracterizar un determinado modo del ser del discurso, [...] se trata de una palabra que debe ser recibida de cierto modo y que en una cultura dada debe recibir un estatuto determinado» (337-338). 
intervenciones públicas. No olvidemos que su entrada al campo cultural se complementa con sus acciones como maestra y con sus discursos. Considerada la primera mujer conferencista en Argentina (como también la primera mujer directora de una escuela mixta y la primera mujer que ocupa un cargo en la Comisión Nacional de Escuelas), ella inaugura, con sus conferencias y, nuevamente con mucha dificultad, «este espacio de acción decididamente ajeno a la casa, frente a la tertulia y la velada literaria que promueven sus compañeras, a medio camino entre lo doméstico y lo público» (Zuccotti 102).

La escritora se moviliza en esta práctica de hablar en público, una manera de poner en acto sus ideas y componer una escena con sus palabras, al punto de arriesgar el cuerpo en ellas. "Hablar en público» (como ocupar un cargo) es, de alguna manera, hacerse pública, darse a conocer y quedar expuesta.

Prueba de ello fue la virulencia y la crispación que estas actuaciones provocaron, de las cuales la crítica ha dejado constancia, como lo sucedido a la salida de su conferencia en Chivilcoy $(1868)^{6}$. No es mi intención repetir estas reacciones, que llegaron a la injuria, y fueron provocadas, como decía, por lo que Manso denuncia y por cómo lo denuncia: un tono enfático, que percibimos en el lenguaje directo y la fuerza elocutiva de sus escritos, plagados de interjecciones, interpelaciones, acusaciones frontales, aspavientos, etc. Un ethos que permite articular cuerpo y discurso (Maingueneau 209), una enunciación que le confiere una "enérgica corporalidad" y una voz indisociable de un cuerpo enunciante. La misma que cabe suponer en sus presentaciones públicas según se desprende del consejo que Sarmiento le transmite: "Baje U., pues la voz en sus discursos y en sus escritos» (OCXXIX, 222). Porque si algo caracteriza su estilo es la invectiva, la modalidad apelativa, la confrontación, ante la que uno de sus detractores le recomienda: "Tome señora, tome por Dios algunos calmantes...» (Santa Olalla ctd. en Velasco y Arias 324).

Lelia Area sugiere que el fracaso de Álbum de señoritas se debe precisamente a esas marcas discursivas: "su retórica tuvo el poder de fascinar por la brusquedad y la fuerza de la palabra publicística; sin embargo, esa palabra dura, fuerte, sin ornatos,

6. En su conferencia sobre la «Reforma Religiosa en Europa», en la Escuela Catedral Norte, que no puede terminar, recibe pedradas e insultos y le arrojan asafétida. El hecho queda documentado en su correspondencia con Sarmiento. estuvo -en boca de esa mujer- condenada al fracaso» (68). Pero es Liliana Zuccotti quien mejor ha resumido las características de esta tonalidad: "Juana grita, su estilo grita» (Gorriti, Manso 107), muy lejos del susurro que, se supone, caracteriza a las mujeres, avanzando contra todas las reglas tácitas y explícitas del «buen decir» (106). En cierta forma, se sitúa en el otro extremo del decir cortés o la simulación de Juana Manuela Gorriti, cuyo semblante opta estratégicamente por la mesura y por preservar, en lo posible, su imagen pública, justo la que Manso dejó al descubierto.

Podemos medir, en estos dos estilos tan disímiles, las dificultades de estas mujeres por obtener un reconocimiento profesional. Podemos detectar, en la prevención de la primera o en la injuria que recibe la segunda, la pesada carga de un otro sancionador, siempre hay un amo (un "tutor perpetuo" dice Manso ${ }^{7}$ dispuesto a esgrimir la vara del género: bien sea Sarmiento, los críticos de la época, las Damas de Beneficencia, la Iglesia o el marido:

Lo que ha hecho la Iglesia es remachar nuestras cadenas por la dirección espiritual que nos coloca entre dos dueńos -el de la conciencia lo es el confesor y del cuerpo que lo es el marido-: resultando de este estado de cosas, una monstruosidad espantosa (Manso ctd. en Zuccotti, Entre la pose 365).

La monstruosidad asoma de nuevo en este secuestro de la conciencia y el cuerpo de las mujeres, uno de los ejes fundamentales de la «emancipación moral» que la escritora defiende a ultranza y ante el que eleva su voz. ¿Es la gravedad de esta situación histórica la que explica el calificativo de "monstruosidad espantosa»? Lo cierto es que la monstruosidad siempre aparece ligada en su escritura con un desajuste, con la falta de proporción, con un exceso. En este caso, con la desapropiación absoluta del ser de las mujeres, que resulta desmedida.

Pero a efectos discursivos, lo que me interesa es cómo la omnipresencia de este otro se erige en escena fundante de la voz autorial. Los hombres, esos dueños de las mujeres que dicen «mina mulher -com a mesma entonaçáo de voz com que diz- meu

7. «Con un tutor perpetuo que a veces es lleno de vicios y de estupidez, la mujer tiene con todo que bajar la cabeza sin murmurar, decirle a su pensamiento no pienses, a su corazón no sangres, a sus ojos no llores, y a sus labios reprimid las quejas!» (ÁS, i, 4, 1954). 
cavallo, minhas botas» (OJS, I, 13, 1852), hablan y son hablados en estos textos. Figuran como un permanente recordatorio de la tachadura que ejercen, a la vez que funcionan como una puesta en voz de quien escribe: «Por qué se ahoga en su corazón desde los mas tiernos años, la conciencia de su individualismo, de su dignidad como ser, que piensa, y siente? repitiéndole: no te perteneces á ti misma, eres cosa y no muger?» (ÁS, I, 5, 1854).

La simulación de estas recusaciones hace de la invectiva una marca de estilo en Manso. Entre la denuncia y la demanda, sus escritos oscilan del reconocimiento personal al profesional y al colectivo. La necesidad de suscripciones se combina con sus necesidades económicas, la necesidad de ilustrar a sus lectoras se acompaña de la necesaria compensación que precisa el oficio de las escritoras ${ }^{8}$. Al inaugurar el Álbum declara: "Solo pido un poco de simpatía» (ÁS, I, 8, 1954). Una simpatía unida a las suscripciones porque las descalificaciones tienen un precio, el oficio no se sostiene solo con el crédito personal y simbólico que pudiera rendirle el público.

La estrategia sirve en términos retóricos para captar la atención de sus destinatarios y la complicidad de sus lectoras. Pero en la interacción discursiva de la persuasión se busca tanto la adhesión como se afirma la presencia de la locutora. La firmeza de las palabras en Manso, continuamente enarboladas en una potente tonalidad y la presencia fantasmática de oponentes, modulan la encarnadura de su discurso escrito. La fuerza de esta voz se hará extensible al cuerpo de la persona en sus discursos orales.

Los indicios que libera esta enunciación resultan definitivamente desmesurados y desproporcionados («escandalosos» y "espantosos»). Ante la amenaza de la descalificación histórica que han sufrido las mujeres, no cabe más que componerse a partir del énfasis: efecto de un decir que a su vez despierta efectos adversos. La pasión (como la feminidad) es performativa, solo puede realizarse en acto. $Y$ en el acto de hablar /gritar se afirma Manso, ahí encuentra la modalidad que la sustenta, en donde pone el cuerpo, y cuerpo y lenguaje quedan afectados. Se

8. De esta manera, como apunta María Vicens, «para Manso lo personal, sin duda, es político», al hacer de su propia experiencia, una experiencia colectiva: «Manso piensa en la escritura como una carrera literaria posible para las mujeres y a sus lectoras, como destinatarias a quienes es necesario entretener y seducir, además de ilustrar, para poder mantener vivos sus proyectos ideológicos, pero también comerciales y profesionales» (60). trata fundamentalmente de la relación con ese otro, tan recusado como exhortado que pone en juego lo más íntimo de su ser. La invectiva lo sostiene y la ofensa recibida conforma a quien la recibe. Lo sabe bien la autora. Prueba de ello es el guiño inesperado que dirige a los hombres:

Sería curioso el ver lo qué harían los señores hombres sin nosotras en toda la extensión de los globos habitados! Qué spleen, qué tardío arrepentimiento!... [...] El hombre te maldice o te adora, te insulta o te ensalza, y gira siempre en derredor de ti como la mariposa en torno a la llama!... [...] Y en fin, guerreros o poetas, comerciantes o médicos, abogados o agiotistas, artesanos o agricultores, sabios o ignorantes, científicos o legos, todos venís a pedir que se os haga felices, como si Dios hubiera depositado vuestra dicha en nuestras manos! (ÁS, I, 103, 1854).

Los términos se invierten en esta reflexión. Las mujeres, blanco constante de escarnio o elogio, aseguran la existencia de los hombres. Los hombres... ¿qué sería de ellos sin el objeto de deseo y de dominio que los constituye?

\section{La autora monstruosa}

Uno de los dos únicos retratos que nos llega de Manso (escaso material para quien puso el cuerpo en conferencias y discursos) compone una pequeña efigie dedicada a Bartolomé Mitre. Zuccotti comenta la pose que aparece en esta fotografía, una mezcla de firmeza varonil, desaliño y mirada perdida que la ha inmortalizado y que se ha propagado en historias y manuales de la literatura o la educación, y advierte: "no se trata de una mujer hermosa» (Entre la pose 370). Pero no se trata de reproducir esta mirada masculina, no importa la imagen sino el uso que los contemporáneos y la historiografía hicieron de ella. Zuccotti recalca que la imagen masculina, "grotesca», de Manso se proyectó hacia toda su obra (Entre la pose 370).

Porque si la profesionalización de las escritoras resulta ya irremediable, ese otro sancionador que antes planteaba impone un peaje de entrada. Deben escribir conforme a su condición femenina, al «bello sexo» (que reza el título de algunos semanarios) y que no solo las segrega, sino que naturaliza el calificativo al que se deben. Con frecuencia, los aplausos que las autoras reciben encumbran más la persona que la obra: 
El texto y su autora se prolongan en un cuerpo único, indiscernible, y aun los comentarios elogiosos que reciben escritoras como Juana Manuela Gorriti o Eduarda Mansilla exaltan, junto a la belleza de la escritura, la belleza de sus autoras. Cada libro reclama también a la autora como un personaje, un personaje codificado: romántico, sensible, etéreo; un personaje que Manso eludió en la constitución de su imagen pública (Zucotti, Entre la pose 370).

De paso, el fantasma de la pérdida de la diferencia (de los sexos y de los privilegios masculinos) que esta participación propició se mantiene a raya.

La historia literaria nos ofrece numerosos ejemplos de masculinización de las escritoras, incluso en forma de falso elogio, como una manera de apuntar sus logros en la única genialidad posible, la de los hombres, o como una manera de insinuar una excepcionalidad anómala. El propio Sarmiento escribe en su diario de viajes de Nueva York: «La Manso, a quien apenas conocí, fue el único hombre en tres o cuatro millones de habitantes en Chile y la Argentina que comprendiese mi obra de educación y que inspirándose en mi pensamiento, pusiese el hombro al edificio que veía desplomarse. ¿Era una mujer?» (OC XLIX, 294).

Poco después, cuando estrecha su amistad, se dirige a ella para consolarla de los agravios de Chilvilcoy, y le escribe:

Le he mandado su fotografía á Mrs. Mary Mann, y está Vd. sentada en su hogar, y colocada en las afecciones y la estimación al lado de Emerson ó de Horacio Mann, ó de Longfellow. Entre los suyos, continuará siendo la Juana Manso, una mujer gorda, vieja, pobre, es decir, nada ó poquísimo. Pero continúe Vd. su trabajo (OCXXIX, 141) .

Extraño consuelo el que oferta Sarmiento, que nos muestra hasta dónde Manso encarnó el negativo de un ideal femenino que exigía también un origen ilustre de clase. La fotografía viaja hasta EUA y parece

9. También en la carta que dirige al director del Correo del Domingo en la misma fecha (1868) comentando la ofensa: «El genio, sufre entre nosotros; peor si es mujer, desvalida, impotente contra la opresión del desprecio ó de la indiferencia pública. Juana Manso ha visto transcurrir la vida sin que una mirada simpática haya vuelto hacia ella al oirla recitar sus versos. La única de su sexo que ha comprendido que bajo el humilde empleo de maestro está el sacerdocio de la libertad y de la civilización» (OC XXIX, 139). que solo allí obtendrá el merecido reconocimiento ¿de su obra?, dado que en Argentina ya ha sido tachada por su cuerpo y por su posición social. Un cuerpo que, en otro lugar, ella misma define como «mal entrazado» ${ }^{10}$.

Pero quisiera oponer a estos ya tan repetidos tópicos una escena menos conocida. Se trata de la presentación que aparece en el segundo número de $O$ jornal, titulada "Quem eu sou e os meus propósitos», dirigido explícitamente a las lectoras. El retrato comienza alertando de que no dará a conocer su biografía ni mostrará sus sentimientos al modo romántico.

La autorrepresentación exige un irónico ejercicio de distanciamiento, un juego de desdoblamientos en los que ella misma se contempla y en los que ella misma se coloca en el centro de la escenografía autorial que arma. Alternando la $1^{\text {a }}$ y la $3^{\mathrm{a}}$ persona se pregunta: «¿Quem sou eu», "¿Quem é ella?». Entre el enigma y la apelación lectora, anticipa las conjeturas con las que será recibida: «¿Quem é ella? Será velha ou moça? Bonita ou feia? Elegante ou excêntrica? [...] Ah! sim; dezejaes saber, ou vos perguntaes umas ás outras, se conhecem a Redactora do JORNAL DAS SENHORAS? Não serei eu quem vos tire da curiosidade» (OJS, I, 11, 1852). Frente a posibles valoraciones, se niega a definirse. Frente al más que seguro elogio o descalificación... del cuerpo, guarda el secreto, lo que podría tomarse como una estrategia defensiva si no fuera porque tiene solo treinta y tres ańos, y porque a continuación los papeles se invierten, de ser objeto de la mirada pasa a sujeto agente de esta.

Cuenta entonces, a propósito de Esteban Echeverría, que sus Rimas la apasionaban y que lo imaginaba "hermoso, mitad hombre mitad arcángel», "con grandes ojos azules, de mirar profundo y sereno".

Pero «Ai! desgraçada!», dice. Cuando se lo presentan descubre que era feo, picado de viruela, con ojos pequeńos y bizcos (sic). Y cuenta que, al verlo, exclamó: «Eu dei um grito involuntario, e esclamei: Pois este!... é Echeverria!!!Este!» y aclara que según

10. Lo cual no le impide establecer un parentesco entre genios: «Sin pretender asemejarme a Beethoven, que ha revelado al mundo las leyes de la melodía, hay puntos de contacto entre su vida y la mía. Como yo, y más que yo, él era pobre; vivía en la soledad más absoluta del espíritu. Era sordo, y como yo, mal entrazado. Al querer dirigir una de sus óperas lo silbaron, como se ríen de mí todas las mujeres de Buenos Aires» (ctd. en Velasco y Arias 78). 
la entonación de su voz, era lo mismo que decir «este monstro! Foi uma dor mortal a que eu senti vendo o meu ideal despedaçado» (OJS, I, 1, 1852). Nunca más pudo volver a leer las Rimas.

No sé los efectos que podrían causar en la época estas apreciaciones sobre Echeverría pero más allá de pagar con la misma moneda, me interesa destacar la noción de autoría que Manso expone aquí. A la discordancia entre talento y aspecto se suma la conveniencia de deslindar la persona del escritor (al menos en su físico, esto es, de su cuerpo), a riesgo de "contaminar» la lectura, inclusive la de los hombres menos favorecidos ${ }^{11}$.

Pero la propuesta avanza mucho más al reclamar la construcción imaginaria que debe rodear a los artistas:

Os poetas e a pintura devem sempre ver-se de longe; porém os poetas principalmente devem olhar-se a travez do prisma caprichoso da ilusão. Assim se goza dobradamente, e as vezes estima-se na fantasia um ser imaginário. (OJS, I, 11, 1852).

Se trata de mirar de lejos a los poetas o mirar de lejos las obras para investirlos imaginaria y fantasmáticamente. Así puede gozarse y amar a ese ser que no existe más que en la fantasía, puede y debe «inventarse» a un autor. Todo ello a condición de liberarlo de la pesada carga del cuerpo, la misma con la que cargó la propia Manso. Para ella, la identidad autorial bien merece esta evanescencia, este fantasma.

¿Quién es ella? La única definición en la que la editora se deja apresar es en la de "femme auteur», tal y como expone. Solo en el idioma extranjero encuentra un significante para inscribirse como mujer escritora que comienza por reinventarse a sí misma. Se trata de una expresión francesa que seguramente le otorga cierta elegancia y cosmopolitismo. Pero se trata también de un binomio impronunciable aún en su lugar de origen, un binomio en el que no encaja y cuya distancia se mide con una lengua foránea.

Finalmente un giro inesperado cierra esta presentación. Vuelve a insistir en que no quiere hablar de sí, pero aclara que no es bizca ni picada de viruelas y pone por delante su propósito de escribir sobre la mujer («la porción más bella de la humanidad»), sus

11. También en La familia del Comendador aparece la investidura imaginaria del amor que libra de las trazas del cuerpo: «Es verdad que suele decirse que "la belleza está en los ojos de quien ama», y si así no fuese, pobres feos y feas"» (70). derechos y su misión. Las escritoras no deben ser las más bellas ni la mujer lo es por naturaleza pero, en su conjunto, componen la belleza de la humanidad.

\section{La feminidad monstruosa: género, cuerpo y moda}

Desde el primer número de $O$ Jornal, Manso se formula la pregunta: «Não é máo principio para uma Jornalista começar por definir aquillo que é indefinivel. A mulher! O que vem a ser a mulher? Vejamos. Ardua é a questáo! E apezar de tudo todo o mundo a define segundo lhe apraz» $(O J S, \mathrm{I}, 5,1852)^{12}$.

$\mathrm{El}$ interrogante sirve para poner en danza la voz autorial mediante la composición de distintas escenas en las que interroga a los hombres sobre esta cuestión: «Ha sujeito que em fin na sua vida lhe foi possivel fazer uma conquista amorosa, ou porque é feio, ou desageitado, perguntai-lhe, o que é a Mulher? E elle logo vos respondera -a Mulher! é um demonio com saias, uma cobra, um monstro, uma furia, etc., etc.» (OJS, I, 5, 1852).

El texto compone un catálogo de atributos femeninos desde la perspectiva masculina que se alternan con los comentarios de la redactora. Para aquellos a los que les robó el corazón, ella sería «o symbolo da inconstancia; diz que é traidora, falsa; em fim é tudo quanto lhe antolha o seu amor proprio offendido!», a lo que la escritora contesta: «Valha-me Deos! pobre mulher!». Para los maltratadores que no consiguen retenerla, «a mulher é perfida porque náo teve mais paciencia que Job para soffrer e tolerar! «. Para no resultar excesivamente maniqueísta, no solo expone agravios sino que también recoge algunos de los elogios que con frecuencia recibe. Un joven apasionado dice que «as mulheres são anjos consoladores, divindades, etc., etc.», sin concederle demasiado crédito. De hecho, la estrategia no consiste tanto en mostrar los tópicos del género sino en presentarlos en boca de hombres y evidenciar que provienen de sus circunstancias, desmintiendo así la naturaleza de tales atribuciones, que se descubren partidistas y tendenciosas. Inclusive algunos poetas, que comprenden que la mujer no ha venido al mundo para servir de «machine à propagation» (sic), el día que sufren una desilusión amorosa, "então elles gritão com o resto dos homens - por fim: é mulher» $(O J S, I, 5,1852)$.

12. Se trata del artículo titulado "A mulher», que no aparece firmado pero que por su estilo y contenido puede ser atribuido a Manso. 
El catálogo se extiende a los tratados médicos, los desvaríos de la frenología y el relato mítico de Adán y Eva (en donde la mujer es causa de perdición). Todo ello para concluir diciendo que no sabe qué es una mujer y que "assim estamos neste mundo; insultadas por estes, elogiadas por aquelles, e desconhecidas e menoscabadas por todos» (OJS, I, 5 , 1852). No se trata de hacer de ella un enigma ni de estigmatizar su complejidad. La cuestión de fondo que este diálogo figurado resalta es hasta dónde la feminidad se construye como un campo de opinión por parte de los hombres, sin que ellas tengan nada que decir. Quien por experiencia podría manifestarse, se muestra cauta, para no caer en la red de intereses que la han ido tejiendo. En el juego de preguntas y respuestas con el que se presenta esta discusión, el travestismo discursivo revela que la mujer queda totalmente cercada por las palabras y la mirada de los hombres de a pie, de letras y de ciencias $^{13}$.

En «Educación de las mujeres» ${ }^{14}$ retoma la misma estrategia y avanza un paso más. La voz puesta en lugar de los hombres no solo reproduce su discurso y declama cómo hablan de ellas sino cómo las construyen al precio de su ausencia. No solo denuncia que es su ignorancia la que las demoniza. Frente a los que hablan sin saber de ellas se alza la voz de quien sí sabe cómo ellos piensan y conoce su lenguaje.

En el artículo salta de nuevo la condición permanente tutelada de las mujeres, en especial la que esclaviza su imagen ${ }^{15}$ :

La mujer es esclava de su espejo, de su corsé, de sus zapatos, de su familia, de su marido, de los errores, de las preocupaciones; sus movimientos se cuentan, sus

13. Pocos meses después, en «Educación de la mujer» la desautorización llega más lejos y en forma de acusación respecto a los avances de las distintas disciplinas, a pesar de los cuales no se ha podido descifrar a la mujer. De nuevo no se trata del enigma femenino sino de la ignorancia de los hombres.

14. Publicado primero en La Ilustracion argentina (segunda época, 18 de diciembre de 1853, pp. 5-18), se repite en el Álbum de Señoritas no 8, 17 de febrero, 1854.

15. La misma cuestión se plantea en «Emancipación Moral de la Mujer» en el Álbum: "Con efecto, una gran nación como la Inglaterra, la mas libre del mundo, que tiene en su seno millares de instituciones filantrópicas, y que ha hecho á la humanidad el relevante servicio de extirpar el comercio de la carne humana, suprimiendo el tráfico de la exclavatura, no podía abrigar en sí misma una monstruosidad semejante, como la de conservar a la muger en el estado de la mas degradante y torpe esclavitud» (I, 4, 1854). pasos se miden, un ápice fuera de la línea prescripta, ya no es mujer, ¿es el qué?... un ser mixto sin nombre, un monstruo, ¡un fenómeno! (ÁS, I, 105, 1954).

Manso retrata así las restricciones de un ideal y formula una noción de género que podemos considerar vigente: el género como horma de lo que no termina de calzar.

El espejo se presenta como uno de los peores enemigos de la mujer, obligada a mirarse en él y a reconocerse como tal, aprisionada en su imagen, cautiva de la servidumbre del cuerpo (torturado por el corsé y los zapatos) y de la sumisión a la familia (patriarcal). El espejo se convierte entonces en lupa: una estricta vigilancia encierra la feminidad en una «línea prescriptiva». En otro momento, al afirmar que es el hombre quien escribe las leyes, dice: «el círculo que traza en derredor de la mujer es estrecho, inultrapasable» (ÁS, I, 4, 1854).

Lo revelador de esta línea prescriptiva es que no delimita la frontera entre los sexos. Quien no entra en la horma ya no es ni mujer ni hombre. "Es un ser mixto sin nombre» declara, un monstruo, un fenómeno... diríamos: se hace queer. Como el «bicho de siete cabezas» con el que Manso se identificaba al dirigir un periódico. O como la protagonista de Los misterios del Plata. No podemos afirmar que se travista exactamente de hombre pues tras el bigote y la capa militar, esconde a su hijo. ¿Qué es? ${ }^{16}$

No se trata solo, como exponía al comienzo, de un lenguaje afectado que requiere moderación, sino del cuerpo igualmente afectado que lo enuncia, imposible de contener tanto en las prescripciones que expresa como en la intensidad discursiva que lo atraviesa.

Los ideales de género hacen del cuerpo una cárcel monstruosa que, como la moda, obligan a rigores arbitrarios, como cuando en pleno verano, por seguir la novedad parisina, las mujeres argentinas deben adoptan vestimentas de invierno: «hagamos más, ese sacrificio a la imitación» (ÁS, I, 9, 1854), exclama.

Sin duda las alusiones a la moda francesa o española pueden ser tomadas como una forma de evaluar el mimetismo en la construcción de la identidad nacional o los potenciales riesgos del consumo, tal y

16. La descripción se publica en diciembre de 1853, en $L a$ Ilustración Argentina. En febrero de 1854 aparece en Álbum de Señoritas. En ambos casos forma parte de artículos reivindicativos alrededor de la emancipación o la educación de la mujer. Al tono combativo y acusatorio, tan habitual en Manso, se suma la insistencia. 
como ha demostrado Susan Hallstead (2016). Pero también forma parte de una tecnología corporal femenina y, tal y como Manso la entiende, de la repetición mimética que conlleva el género. A propósito de la moda española, comenta:

Es una aberración, lo conozco, pero me gusta mas la mantilla á la española, y mas que todo la libertad, la invencion, esto de imitar un figurin, parece una cosa, así como la de hacer una muñeca á imitación de la gente, aquí es al reves, es la gente que se torna muñeca (ÁS, 1, 8, 1954).

«La gente (la mujer) se torna muñeca». Los dictados de la moda fetichizan el cuerpo de las mujeres, en donde lo femenino queda encarnado siniestramente en la muñeca. Pero lo peor no viene solo de esta cosificación sino de la serialización a la que conducen las normas del género, en donde la mujer es el doble de la muñeca y no a la inversa. La «imitación» del figurín (un supuesto original sin vida) no deja lugar para la invención ni la libertad. No es posible ser mujer de otra manera. Lo que resulta sin duda una «aberración», sumado a preferir la moda española (con las correspondientes connotaciones coloniales que ello supone).

Este cuerpo fetichizado no escapa tampoco a la maternidad. "Máquina procreativa» es la expresión con la que la escritora se refiere más de una vez a esta función reproductiva. Una pregunta asalta en «La emancipación moral de la mujer»: "Por qué reducirla al estado de la hembra cuya única misión es perpetuar la raza? Por qué cerrarles las veredas de la ciencia, de las artes, de la industria, y así hasta la del trabajo, no dejándole otro pan que el de la miseria, o el otro mil veces horrible de la infamia?» (ÁS, I, 5, 1954).

Es preciso detenerse en el argumento, que conduce de la madre como único destino natural para la mujer al callejón sin salida de la prostitución. La maternidad la reduce a un "estado de hembra», en donde la biología estrecha su margen identitario. Pero todavía llega más lejos: convierte la correspondencia obligada entre género y sexo en un estado («estado de hembra»), por tanto, en una circunstancia transitoria que la escritora termina por desnaturalizar.

Nada que la educación de la mujer y la instrucción social no puedan salvar. No pongo en duda la defensa de la maternidad republicana en Manso. Pero al proclamar el deber de construir la nación como madre y esposa, inclusive como maestra y escritora, emergen las discordancias entre los modelos, los desajustes con los figurines y los cuerpos monstruosos. Que los imperativos patrióticos sean necesarios no asegura que se amolden a la(s) naturaleza(s) de la mujer(es), como no se amoldaban los imperativos culturales del género, en el trecho que media siempre entre el ser y el deber ser. Porque, como reconoce la autora ante el cierre forzoso del Álbum de señoritas, cuando pide disculpas por su lenguaje y su estilo, y no le queda más que afirmarse en su yo: «cada cual es como es y no como debería ser» (ÁS, I, 41, 1954).

Quizás la condición monstruosa de la escritora venga de esta feminidad monstruosa de por sí. Quizás por ello, en sus reivindicaciones, tiende a borrar la diferencia anatómica, a disolver el sexo:

Dios no es contradictorio en sus obras, y cuando formó el alma humana, no le dio sexo. La hizo igual en su esencia, y la adornó de facultades idénticas. Si la aplicación de unas y de otras facultades difiere, eso no abona para que la mujer sea condenada al embrutecimiento (ÁS, I, 47, 1954).

Sin embargo, esta disolución atañe al alma, no al cuerpo; concierne a las facultades y no a la anatomía. La igualdad se asegura entonces en la disolución de sexos y en el borrado de la diferencia corporal.

Merece la pena traer a colación un episodio de $L a$ familia del comendador para matizar esta conclusión. $\mathrm{Al}$ describir al personaje de Mauricio, el discurso traiciona la buena voluntad de la autora: «difícil era clasificarlo de mulato porque ninguna de sus facciones lo traicionaba» (41). Es uno de los episodios mediante los cuales Adriana Amante razona que, tras la defensa contra la esclavitud en Manso, se cierne el límite de la raza (366). De nuevo, las clasificaciones no encajan con el cuerpo. De nuevo, el cuerpo traiciona. Podemos afirmar entonces que la esclavitud es a la raza lo que el género al cuerpo, y que el límite de Manso no es el sexo ni el género, sino justamente el cuerpo.

La escritora monstruosa viene determinada por el carácter monstruoso que impone la feminidad, decía. En una de sus cartas a Sarmiento, en un medio que he venido considerando como un espacio privilegiado de escenografía autorial, Manso se autorrepresenta de un modo un tanto enigmático: "porque nosotras las basbleu, somos unos animales anfibios, cuyo único valor es la pollera; y desde la invención de los mirińaques, ni eso, porque ya no hay mujeres sino amazonas» (ctd. en Velasco y Arias 315). 
La correlación de identificaciones no puede ser más significativa. El término «basbleu» ${ }^{17}$, en francés, de género masculino, utilizado para menoscabar a las mujeres con pretensiones intelectuales y literarias, se desliza hasta las amazonas, las mujeres guerreras que la tradición presenta como virilizadas. Si la falda (la vestimenta) aseguraba el valor de la feminidad, el miriñaque, que la ahueca, viene a enrarecerla. No se sabe qué esconde el cuerpo como no se sabe qué es lo femenino. Todo ello se conjuga en la extraña condición anfibia, es decir, monstruosa, de ese binomio imposible que aúna ser mujer y ser escritora en la Argentina de mediados del siglo XIX.

\section{Bibliografía}

Amante, Adriana. Poéticas y políticas del destierro. Argentinos en Brasil en la época de Rosas. Buenos Aires: Fondo de Cultura Económica, 2010.

Area, Lelia. Álbum de Senoritas de Juana Manso: periodismo y frustración para un proyecto domestico de fundar una nación. Buenos Aires: Feminaria, 2005.

AuzA, Néstor Tomás. La Aljaba: dedicada al bello sexo argentino, 1830-1831. Buenos Aires: La Plata: Archivo Histórico de la Provincia de Buenos Aires «Dr. Ricardo Levene»: Asociación Amigos del Archivo Histórico de la Provincia de Buenos Aires; Instituto Bibliográfico «Antonio Zinny», 2004.

Batticuore, Graciela. La mujer romántica. Lectoras, autoras y escritores en la Argentina:1830-1870. Buenos Aires: Edhasa, 2005.

Fletcher, Lea. "Juana Manso: una voz en el desierto». Lea Fletcher (eda.). Mujeres y escritura en la Argentina del siglo XIX. Buenos Aires: Feminaria, 1994: 108-120.

Foucault, Michel. «¿Qué es un autor?». Entre la filosofía y la literatura. Obras esenciales vol. I. Barcelona: Paidós: 1999 (1969): 329-360.

Hallstead, Susan. «Modas y máscaras de la civilización: Juana Manso frente al consumo». Saga: Revista de Letras, 4, Segundo Semestre (2016): 75-119.
Maingueneau, Dominique. «El enunciador encarnado. La problemática del Ethos». Versión. Estudios de comunicación y politica, 24, (2010): 203-225.

Manso, Juana. O Jornal das Senhoras. Modas, litteratura, bellas artes, theatros e critica. Rio de Janeiro: Typographia Parisiense, 1852.

Manso, Juana. Álbum de Seńoritas. Literatura, Modas, Bellas Artes y Teatros. Buenos Aires: Imprenta Americana, 1854.

Manso, Juana. La familia del comendador y otros textos. Buenos Aires: Colihue: Biblioteca Nacional de la República Argentina, 2006.

Masiello, Francine, comp. La mujer y el espacio público. El periodismo femenino en la Argentina del siglo XIX. Buenos Aires: Feminaria, 1994.

Meyer, Constanza V. «Cuerpo, sexo y comida: un triángulo femenino». Lea Fletcher (eda.). Mujeres y cultura en la Argentina del siglo XIX, Buenos Aires: Feminaria, 1994: 121-126.

Sarmiento, Domingo Faustino. Obras completas. Tomo XXIX. Ambas Américas. Buenos Aires: Imprenta y Litografía «Mariano Moreno», 1899.

Sarmiento, Domingo Faustino. Tomo XLIX. Memorias. Buenos Aires: Imprenta y Litografía «Mariano Moreno", 1900.

Velasco y Arias, María. María: Juana Paula Manso. Vida y Acción, Buenos Aires: Talleres Gráficos Porter Hnos, 1937.

VICENS, María. «Entretenimiento, público y autoría femenina en los periódicos de Juana Manso (1850-1860)». Perifrasis. Revista de Literatura, Teoría y Crítica, 8:16(2017):48-63.

Zuccotтi, Liliana. «Gorriti, Manso: de las Veladas literarias a "Las conferencias de maestra"». Lea Fletcher (eda.). Mujeres y cultura en la Argentina del siglo XIX, Buenos Aires: Feminaria, 1994: 87-95.

Zuссотт, Liliana. «Entre la pose y la palabra». Esther de Miguel (eda.). Mujeres argentinas. El lado femenino de nuestra historia. Buenos Aires: Extra Alfaguara, 1998: 363-379.
17. La expresión es utilizada por Manso en otra ocasión. En los recuerdos de su viaje a EUA, en 1846, al describir la extremada coquetería de las mujeres norteamericanas, apunta: "porque el vestido y el lujo es el pensamiento fijo de toda americana y después de eso las pretensiones literarias, porque todas son lo que llaman los franceses "Bas-Bleues!" " (ctd. en Velasco y Arias 342). 